Original article

\title{
Gender identities in adolescent population: Methodological issues and prevalence across age groups
}

\author{
Riittakerttu Kaltiala-Heino ${ }^{\mathrm{a}, \mathrm{b}, \mathrm{c}, *}$, Nina Lindberg ${ }^{\mathrm{d}}$ \\ a Tampere University Hospital, Department of Adolescent Psychiatry, BOX 2000, 33521 Tampere, Finland \\ ${ }^{\mathrm{b}}$ Vanha Vaasa Hospital, Vierinkiventie 1, 65380 Vaasa, Finland \\ ${ }^{\mathrm{c}}$ University of Tampere, Faculty of Medicine and Life Sciences, 33014 University of Tampere, Finland \\ ${ }^{\mathrm{d}}$ Helsinki University and Helsinki University Hospital, Forensic Psychiatry, P O Box 590, 00029 HUS, Finland
}

\section{A R T I C L E I N F O}

\section{Article history:}

Received 27 May 2018

Received in revised form 11 September 2018

Accepted 14 September 2018

Available online 31 October 2018

\section{Keywords:}

Gender identity

Adolescence

Population study

Mischievous responding

\begin{abstract}
A B S T R A C T
Background: Increasing numbers of adolescents are seeking treatment from gender identity services, particularly natal girls. It is known from survey studies some adolescents exaggerate their belonging to minorities, thereby distorting prevalence estimates and findings on related problems. The aim of the present study was to explore the susceptibility of gender identity to mischievous responding, and prevalences of cis-gender, opposite-sex and other/ non-binary gender identities as corrected for likely mischievous responding among Finnish adolescents.

Method: The School Health Promotion Survey 2017 data was used, comprising data on 135,760 adolescents under 21 years (mean 15.73, ds 1.3 years), 50.6\% females and $49.4 \%$ males. Sex and perceived gender were elicited and gender identities classified based thereon. Likely mischievous responding was analysed using inappropriate responses to biodata and handicaps.

Results: Of the participants, 3.5\% had most likely given facetious responses, boys more commonly than girls, and younger adolescents more commonly than older. This particularly concerned reporting of nonbinary gender identity. Corrected prevalence of opposite-sex identification was $0.6 \%$ and that of nonbinary identification was 3.3\%. In boys, displaying non-binary gender identity increased from early to late adolescence, while among girls, opposite-sex and non-binary identifications decreased in prevalence from younger to older age groups.
\end{abstract}

Conclusion: Prevalence of gender identities contrary to one's natal sex was more common than expected. (c) 2018 Elsevier Masson SAS. All rights reserved.

\section{Introduction}

Gender Dysphoria in DSM-5 [1] refers to a condition in which an individual senses a marked discrepancy between her/his experienced gender and her/his natal sex, and this causes clinically significant distress or impairment in important areas of functioning. Most individuals with Gender Dysphoria have a strong desire to be treated as the other gender (or some gender other than their assigned gender) and/or to be rid of their natal sexual characteristics, and a strong conviction of having feelings and reactions typical of the other gender (or some alternative gender). Transsexualism in ICD-10 [2] refers to a persistent desire to live and be accepted as a member of the opposite sex. This is usually accompanied by a sense of discomfort with or of the inappropriateness of one's anatomical sex and a wish to undergo

\footnotetext{
* Correspoding author at: Tampere University Hospital, Department of Adolescent Psychiatry, BOX 2000, 33521 Tampere, Finland.

E-mail address: merihe@uta.fi (R. Kaltiala-Heino).
}

surgery and hormonal treatment to make the body congruent with the preferred sex. Gender incongruence refers to an incongruence between one's natal sex and present experienced gender, and is also the term to be introduced instead of Transsexualism in the forthcoming ICD-11 [3]. "Transgender" is used as an umbrella term to refer to a variety of gender identities incongruent with one's natal sex [4]. Not all who identify as transgender necessarily suffer from dysphoria. Healthy children vary considerably in gender expression [5]. Of children with even a marked incongruence between their natal sex and experienced gender, about four out of five are known to develop towards identifying with their natal sex at puberty [6]. In some children displaying gender incongruence, gender dysphoria intensifies at puberty [6]. Childhood onset gender dysphoria intensifying at puberty is assumed to be so persistent as to warrant medical treatment. Currently, according to the so-called Dutch model of care, the development of secondary sexual characteristics can be halted from the early stages (Tanner Ii-III) of puberty, and cross-sex hormonal treatments initiated from about age 16. Surgical treatments are mainly available for legal adults $[7,8]$. 
The number of adolescents contacting specialized gender identity services has risen considerably in the last decade throughout Europe and North America $[9,10]$. At the same time, the overrepresentation of natal boys identifying as girls seen earlier among gender-referred minors has changed to an equal male:female ratio, or indeed to a preponderance of natal females $[10,11]$. In Finland gender identity services for minors (two in the country) were introduced in 2011. Since then, the annual number of referrals had increased five-fold by 2016 and 2017. In Finland most adolescents seeking medical treatment in order for their body to conform with their gender identity do not fulfil the eligibility criteria of the original Dutch model of care [11], for example because they initially experienced onset of gender dysphoria in the late stages of pubertal development or suffer from severe mental disorders which predate the onset of gender dysphoria. Research on adolescent onset gender dysphoria is scarce, and optimal treatment options have not been established [12]. The reasons for the sudden increase in treatment-seeking due to adolescent onset gender dysphoria / transgender identification are not known [13].

As far as we know, no state-of-the-art epidemiological studies have been presented on the prevalence of Gender Dysphoria or Transsexualism in general adolescent population. In a few adolescent population survey studies comprising from approximaltey 3000 to 300000 it has been estimated that $0.17-2.7 \%$ of adolescents and young adults identify as transgender $[14,15,16,17,18]$. Of these, Reisner et al. [18] studied a sample identified through being the children of a cohort of nurses, and the other studies recruited participants from school, college or university populations. These studies either elicited sex and perceived gender separately or focused directly on gender without eliciting natal sex. Most recently, Becker et al. [19] estimated the prevalence of gender variance in children and adolescents aged 1016 in a subsample of about nine hundred respondents in a larger health survey. After eliciting the sex of the participants they focused on gender perception and gender expression, asking the respondents to rate to what extent they perceived themselves to be feminine and masculine, and to what extent others found them to behave like a boy / like a girl. They concluded that all in all $4.1 \%$ of the respondents were rated as displaying variant gender experience, and 3.0\% non-conforming gender expression. More gender variance was seen in girls and in younger participants. A Finnish survey explored gender dysphoria in an adolescent school sample using an identity questionnaire widely used in adolescent gender identity services. The findings suggested that among 16 to 18 -yearold upper secondary school students, $2.2 \%$ of boys (95\% CI $0.6 \%-$ $3.8 \%)$ and $0.5 \%(-0.2 \%$ to $1.2 \%)$ of girls displayed potentially clinically significant gender dysphoria [20]. Identifying as transgender or displaying variant gender perception or expression is not the same as a clinical diagnosis, but it is important to gain knowledge about the prevalence of transgender identity or gender variance in the non-referred adolescent population, as this will help in planning training for various professional groups working with adolescents and providing services for them.

Identity formation is among the main developmental tasks occurring during adolescence [21,22,23]. Adolescents and young adults form their identities by actively exploring the identity options available to them and making certain identity commitments [24]. Adolescents are more susceptible to contextual influences and external factors than adults [25]. As identity is expected to consolidate towards young adulthood [24], younger adolescents could be expected to explore identity options more extensively than older adolescents, and thus more gender variance could be expected among early and middle adolescents than among late adolescents. On the other hand, becoming aware of and accepting an identity that differs from the mainstream may be more challenging than growing up conforming to social expectations. Hence the development of non-conforming gender identity and becoming aware of it may require more time and therefore middle and late adolescents could be expected to show more gender variant experiences than early adolescents. Since gender variance is tolerated less readily in boys than in girls [6], gender differences in the role of age in forming gender identity could be expected.

It has been demonstrated that some adolescents deliberately mispresent themselves in survey studies, exaggerating their belonging to minorities as well as their problem behaviours, symptoms and psychosocial problems $[26,27,28]$. Consequently the proportion of those belonging to minorities (such as disabled adolescents, immigrants, sexual minorities) appears implausibly high, and associations between minority status and psychosocial problems are overestimated. In relation to gender identity, such overestimation may risk a perception in society that gender variant youth are victims rather than active subjects participating in building the contemporary adolescent community. Two methods of screening for sincerity of responding have been proposed: presenting a sincerity screening question (such as: Have you responded honestly in this survey?) [27,28], and excluding respondents reporting unlikely combinations of extreme responses outside the focus of present interest on topics theoretically not related to the variables of interest for the actual study questions [26]. Particularly in light of the excessive media coverage of gender identity issues [13], gender identity is likely to be a topic which tempts adolescents to give facetious responses. As facetious responses may lead to wildly erroneous conclusions $[26,27,28]$, research needs to address the phenomenon of possible invalid responding.

Thus, prevalence studies provide important basic knowledge on gender identities among young people in the community. However, assessing gender is fraught with difficulty and no study can be complete without an accurate assessment of the truthfulness of responses. The aims of this study were to explore susceptibility to mischievous responding in reporting gender identity in adolescent health survey data, and to assess the proportions of various gender identities among boys and girls in different phases of adolescent development. In more detail our aims were to study

1) to what extent gender identity is a topic susceptible to implausible, likely mischievous responding?

2) report on the prevalence of gender-sex divergence among early, middle and late adolescents, having adjusted for potentially mischievous responses.

\section{Materials and methods}

The School Health Promotion Study (SHPS) by the National Institute for Health and Welfare is a school-based survey designed to examine the health, health behaviours and school experiences of teenagers. The survey aims mainly to produce national adolescent health indicators for the use of municipalities in planning services. The survey is conducted among 8th and 9th graders of the compulsory nine-year comprehensive school and second year students of upper secondary education (upper secondary school and vocational school) which follow completion of comprehensive school. Survey participants in 2017 numbered 139,829. Of these, $48.9 \%(68,333)$ reported that they were boys and $50.4 \%$ (70 539) that they were girls. Of all respondents, $0.7 \%$ (957) did not report their sex, and these were excluded from further analyses. Of the respondents, $52.7 \%$ were in comprehensive school grades 8 or 9 , $25.0 \%$ were attending upper secondary school and $23.3 \%$ vocational 
school. The respondents in the comprehensive school sample had mean (sd) age of 14.83 (0.82) years, those in upper secondary education $16.84(0.83)$ years and those in vocational school 17.29 (2.43) years.

Of the respondents, $2.1 \%(n=2894)$ reported that they were 21 years old or older. These were excluded from further analyses.

\subsection{Measures}

\subsubsection{Sex and gender identity}

The respondents were first asked "What is your sex?", with response alternatives "boy" and "girl". This was intended to elicit the respondent's sex as noted in their identity documents, and was the opening question of the whole survey. Later, in the section of the survey addressing health, respondents were asked about their perceived gender as follows: "Do you perceive yourself to be ...", with response options "a boy / a girl/ both / none / my perception varies". According to sex and perceived gender, the respondents were categorized to one of three gender identities: cis-gender identity (indicated male sex and perceives himself as a boy, or female sex and perceives herself as a girl), opposite sex identification (male sex, perceived to be a girl; or female sex, perceived to be a boy), and other/ non-binary gender identity (independent of sex: perceived to be both a boy and a girl, perceived to be neither a boy nor a girl, variable).

\subsubsection{Biostatistics}

Height (in centimetres) and weight (in kilogrammes) were elicited. Age was calculated from the reported date of birth and date of participating in the survey. The respondents were classified according to age as early (14 years old or younger), middle (15-17 years old) and late (18 years or older) adolescents [29,30].

\subsubsection{Disability}

Disabilities were elicited by asking "Do you have difficulties ... 1) seeing (if you use spectacles or contact lenses, consider your eyesight when using them); 2) hearing (if you use a hearing aid, consider your hearing when using it); walking about half a kilometre, for example around a sports field (if you use a walking aid, consider your ability to walk with it)" with response options "no difficulties", "few difficulties", "a lot of difficulties", “completely unable" coded respectively $1,2,3$ and 4 .. A sum score of disabilities had a theoretical range from 3 (no disabilities / difficulties in seeing, hearing or walking) to 12 (completely unable to see, hear and walk).

\subsection{Implausible, likely mischievous responding}

Children in Finland are required by law to start comprehensive school in the year that they reach the age of 7. Consequently the 8th grade starts during the year when the young person turns 14 . The school year begins in August. The School Health Promotion Survey is implemented late in the spring term, when all those in the 8th grade have turned 14 and oldest of them have turned 15. Occasionally some children start school one year earlier than others. Those pupils would be at least 13 but more likely 14 in the late spring term of the 8 th grade. This means that it is extremely unlikely that anyone younger than 13 could participate the School Health Promotion Survey in the 8th or the 9th year, and age younger than 13 was classified as incorrect reporting of age. Of the respondents, $1.4 \%$ had reported that they were less than 13 years old.

Of the adolescents in the age group studied the majority would have reached or almost reached their adult height. The mean height of the boys was $176.6 \mathrm{~cm}$ ( $\mathrm{sd} 12.2 \mathrm{~cm}$ ), and that of the girls was $165.3 \mathrm{~cm}$ ( $\mathrm{sd} 7.6 \mathrm{~cm}$ ). Cutpoints for the lowest and highest five percentiles were $160 \mathrm{cms}$ and $190 \mathrm{cms}$ for the boys, and $155 \mathrm{cms}$ and $176 \mathrm{cms}$ for the girls. There were striking outliers in reported height. Shorter than $150 \mathrm{~cm}$ for boys and shorter than $140 \mathrm{~cm}$ for girls, and taller than $200 \mathrm{~cm}$ for boys and taller than $190 \mathrm{~cm}$ for girls were classified as invalid implausible reporting of height. Implausible height information was reported by $1.3 \%$ of the respondent

Body Mass Index (BMI) calculated from weight and height $(\mathrm{kg} /$ $\mathrm{m} 2$ ) was used to explore reported body size extremes. BMI equal to or less than $10 \mathrm{~kg} / \mathrm{m} 2$ is so low that such an individual would most likely be hospitalized and not present at school, and at the other extreme BMI equal to or more than $40 \mathrm{~kg} / \mathrm{m} 2$ was likewise considered most unlikely in adolescent population attending school. Such extreme BMIs were classified as implausible reporting of data relevant for calculating BMI (implausible height and weight combination). Implausible BMI was reported by $1.6 \%$ of the respondents

Finnish adolescents with special needs in seeing, hearing or moving may study together with non-disabled students, but a young person with extreme difficulties in all three functions ("completely unable") is not likely to attend those schools that participate in the SHPS. Reporting extreme difficulties (sum score 12) in both seeing, hearing and walking was classified as implausible responding regarding disabilities. Implausible responding regarding disabilities was reported by $0.5 \%$ of the respondents.

\subsection{Statistical analyses}

The proportions of different gender identities and proportions of highly implausible, extreme responses regarding age, height, body size and disability were calculated. Associations between highly implausible responses on these variables and gender identity were studied using cross-tabulations with chi-square statistics. Based on observations from these analyses, a model for excluding those likely to be responding mischievously was created. Differences in responding mischievously according to gender identity were then studied using logistic regression. Being classified as a mischievous responder was entered as the dependent variable and reported gender identity (cis-gender vs. opposite sex identification vs. other/non-binary) was entered as independent variable, controlling for sex and age. Odds ratios with 95\% confidence intervals are presented. Finally, corrected proportions of the various gender identities were calculated and compared between boys and girls in different phases of adolescence (early, middle and late) using cross-tabulations with chisquare statistics. Sex-specific differences in gender identity distributions according to phase of adolescence were confirmed by interaction analysis, entering cis-gender vs. transgender (identifying with opposite sex or other/non-binary) identity as dependent variable and sex, phase of adolescence and interaction term sex* phase of adolescence as independent variables.

\section{Results}

\subsection{Gender identities}

Of the respondents, 93.6\% reported perceived gender congruent with reported sex (rated "boy" when sex was elicited, and reported "boy" as perceived gender, or correspondingly about being a girl). $0.7 \%$ reported perceived gender opposite to reported sex, $4.2 \%$ reported other / non-binary gender identity (felt both male and female, felt neither male nor female or felt that their gender experience varied), and $1.5 \%$ had not responded to the question on perceived gender. The last group was not analysed further. Among those who had responded so that gender identity could be 
classified, $95.2 \%$ of boys belonged to the group classified as cisgender identity, $0.5 \%$ reported opposite-sex identification and $4.3 \%$ reported other / non-binary gender identity, of girls $95.1 \%, 0.8 \%$ and $4.0 \%$ respectively $(\mathrm{p}<0.001)$.

\subsection{Mischievous responding and its relationship with gender identity}

Of those displaying cis-gender identity, $1.1 \%$ had reported age less than 13 years, of those identifying with the opposite sex, $2.8 \%$, and of those with other/ non-binary gender identity, 5.9\% ( $p<0.001$ ).Implausible height information was reported by $1.3 \%$; by $0.5 \%$ of those with cis-gender identity, $7.8 \%$ of those identifying with the opposite sex, and $15.3 \%$ of those reporting other / nonbinary gender identity $(\mathrm{p}<0.001)$.Implausible BMI was reported by $0.9 \%$ of those with cis-gender identity, by $7.4 \%$ of those with opposite sex identification, and by $16.2 \%$ of those reporting other/ non-binary gender identity $(\mathrm{p}<0.001)$. Implausible information regarding disabilities was reported by $0.1 \%$ of those with cisgender identity, $3.4 \%$ of those identifying with the opposite sex, and $9.1 \%$ of those reporting other/ non-binary gender identity $(\mathrm{p}<0.001)$

Respondents reporting implausibly young age, shortness or height or who were calculated to have extreme BMI or reporting both extremely poor hearing, sight and mobility were classified as mischievous responders. Of all the participants, $3.5 \%$ had given such responses $(4.4 \%$ of boys and $2.6 \%$ of girls, $\mathrm{p}<0.001$; of early, middle and late adolescents, $9.9 \%, 2.0 \%$ and $1.6 \%$ respectively, $\mathrm{p}<0.001$ ).

\subsection{Gender identities after adjustment for mischievous responding}

Mischievous responding was associated with reporting other than cis-gender gender identity. Age and sex controlled Odds Ratio (95\% confidence intervals) for mischievous responding was 7.2 (5.8-9.0) among those reporting opposite sex identification, and 18.6 (17.1-20.3) among those reporting other gender identity compared to those with cis-gender identity.

Of subjects with likely mischievous responding style, $65.4 \%$ were classified as with cis-gender identity, $2.7 \%$ with opposite sex identification and $32.0 \%$ with other/ non-binary gender identity, compared to a respective $95.1 \%, 0.6 \%$ and $3.3 \%$ for those not suspected of giving mischievous responses according to the screening method applied $(\mathrm{p}<0.001)$.

Distributions of gender identities among boys and girls in total and among those classified and not classified as mischievous responders are given in Table 1 . Among boys who screened positive for mischievous implausible responding the proportion of those reporting identification with the opposite sex was eight-fold that found in those not screening positive for implausible responding, and 13 -fold for those reporting other gender identity. Among girls, correspondingly, opposite sex identification was twice as common, and other gender identity six times more common among those screening positive for mischievous responding.

Proportions of those reporting cis-gender identity increased among girls and decreased among boys from early ( -14 years old) to middle (15-17 years old) to late ( $18+$ years old) adolescence. Among girls both the proportions of opposite sex and other gender identification decreased from early ( -14 years old) to middle (1517 years old) to late ( $18+$ years old) adolescents. Among boys reported opposite sex identification was slightly lower in middle and late adolescence than in early adolescence but reporting other gender identity was more common among middle and most common among late adolescents (Table 2). In a confirmatory interaction analysis entering cis-gender vs. transgender (opposite sex identification or other/non-binary) identity as dependent variable and sex, phase of adolescence and interaction term sex* phase of adolescence as independent variables, the interaction term was highly significantly $(\mathrm{p}<0.001)$ associated with gender identity.

\section{Discussion}

In this very large survey data on adolescents, more than four per cent of adolescents under 21 years of age reported gender identity incongruent with their sex (not cis-gender). When most likely implausible responding was excluded, over three per cent of boys and over four per cent of girls still reported other than cis-gender gender identity. This is clearly more common than transgender identity or gender dysphoric feelings reported in earlier comparable school / college based survey studies with data from 2008 to $2013[14,15,16,20]$ and also exceeds the prevalence of $2.7 \%$ reported in one more recent school based adolescent data [17]. Our prevalence estimates are very close to those obtained in another recent adolescent population study [19]. However, all those studies are from different countries and used different questionnaires. No earlier measurement with the same questions is available for Finland. It is not feasible to draw conclusions about changes in the prevalence of different gender identities among adolescents in the general population but, taken together, these studies do indeed suggest that a not insignificant proportion of adolescents nowadays experience gender variance.

A novel contribution of the present study is the attempt made to detect implausible responding in gender identity studies. It has been conjectured that some adolescents exaggerate their belonging to various minorities [26,27,28], a tendency which contrasts with another methodological challenge acknowledged in survey studies, namely that of not capturing respondents with conditions and behaviours likely to incur disapprobation (for example, risk behaviours like excessive drinking) or discrimination (for example, sexual minority status) due to a wish for social desirability [31]

Table 1

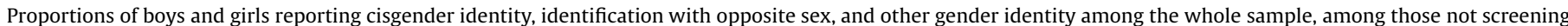
positive and those screening positive for invalid responding, in Finnish adolescents aged less than 21 years. (\%).

\begin{tabular}{|c|c|c|c|c|c|c|}
\hline & $\begin{array}{l}\text { Boys, } \\
\text { all } \\
n=65829\end{array}$ & $\begin{array}{l}\text { Girls, } \\
\text { all } \\
\mathrm{n}=67945\end{array}$ & $\begin{array}{l}\text { Boys, not positive for } \\
\text { mischievous responding } \\
n=62943\end{array}$ & $\begin{array}{l}\text { Girls, not positive for } \\
\text { mischievous responding } \\
n=66183\end{array}$ & $\begin{array}{l}\text { Boys } \\
\text { positive for mischievous } \\
\text { responding } \\
n=2886\end{array}$ & $\begin{array}{l}\text { Girls } \\
\text { positive for mischievous } \\
\text { responding } \\
\mathrm{n}=1762\end{array}$ \\
\hline cis-gender & 95.2 & 95.1 & 96.8 & 95.6 & 59.5 & 76.4 \\
\hline identifies with & 0.6 & 0.8 & 0.4 & 0.8 & 3.2 & 1.8 \\
\hline $\begin{array}{l}\text { opposite sex } \\
\text { other gender } \\
\text { identity }\end{array}$ & 4.3 & 4.0 & 2.8 & 3.6 & 37.3 & 21.7 \\
\hline
\end{tabular}

a Differences between boys and girls are statistically significant at level $\mathrm{p}<0.001$ among all the respondents, among those not screening positive for mischievous

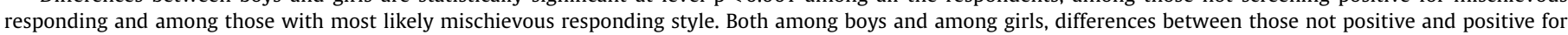
mischievous responding are statistically significant at level $\mathrm{p}<0.001$. 
Table 2

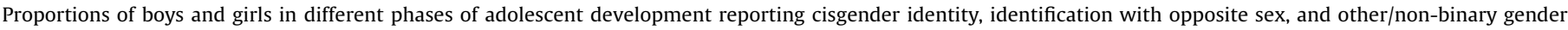
identity, among those respondents in the School Health Promotion Survey 2017 who did not screen positive for invalid responding. (\%).

\begin{tabular}{|c|c|c|c|c|c|c|c|c|}
\hline & \multicolumn{3}{|l|}{ Boys } & \multirow[t]{2}{*}{$\mathrm{p}$} & \multicolumn{3}{|l|}{ Girls } & \multirow[t]{2}{*}{$\mathrm{p}^{\mathrm{a}}$} \\
\hline & $\begin{array}{l}\text { early } \\
n=10997\end{array}$ & $\begin{array}{l}\text { middle } \\
\mathrm{n}=45987\end{array}$ & $\begin{array}{l}\text { late } \\
n=5968\end{array}$ & & $\begin{array}{l}\text { early } \\
n=12144\end{array}$ & $\begin{array}{l}\text { middle } \\
\mathrm{n}=47438\end{array}$ & $\begin{array}{l}\text { late } \\
n=6601\end{array}$ & \\
\hline cisgender & 97.1 & 96.8 & 96.0 & $<0.001$ & 95.1 & 95.7 & 96.0 & 0.003 \\
\hline identifies with opposite sex & 0.5 & 0.4 & 0.4 & & 1.1 & 0.8 & 0.6 & \\
\hline other gender identity & 2.4 & 2.8 & 3.5 & & 3.8 & 3.5 & 3.4 & \\
\hline
\end{tabular}

a Differences between boys and girls are among early and middle adolescents statistically significant at level p $<0.001$ but non-significant among late adolescents.

Exaggerating has been suggested to be mainly due to adolescents attempting to be funny $[26,27,28]$. We demonstrated that reporting gender identity incongruent with natal sex is highly susceptible to such implausible responding. Particularly reporting "other / non-binary" gender identity was far more common among those classified as implausible responders on the basis of reported age, body size and disability than among those not classified as implausible responders. Responding style classified as implausible further influenced findings on prevalence of different gender identities more among boys than girls.

There were more adolescents reporting other/ non-binary gender identity than opposite sex identification. This suggests that gender identity development in adolescence is fluid rather than clearly binary ([19]). Unfortunately, other/ non-binary identity according to our implausibility analysis is also most susceptible to implausible responding. Heterosexism assumes that every individual is heterosexual until otherwise stated and conforms to clearly distinguishable male and female gender roles. Despite the contemporary advances in the rights and visibility of sexual minorities, heterosexism continues to be widespread ([32] [33],). Adolescent boys' attempt to be funny and mispresent themselves as members of sexual and gender minorities and also with an excessive burden of various problems and extreme characteristics cour arise from strengthening heterosexism.

After adjusting for implausible responding, other than cisgender identity was more commonly reported by girls. Among girls the proportions of those reporting opposite sex and other/nonbinary gender identifications decreased from early to late adolescence and cis-gender identity became more prevalent, whereas in boys the proportions of cis-gender identification decreased and the shares of other gender identification increased from younger to older subjects. Gender non-conforming selfexpression is less readily tolerated in boys than in girls [6], and boys mature at a slower rate than girls [17,34,35]. Both these factors could contribute to boys becoming aware of their non-cisgender feelings later than girls. However, among girls, the proportions of transgender identifications decreased with age. A sudden increase in adolescent girls seeking gender reassignment has been observed in gender identity services [10,12]. This rapid increase in recent years in adolescent-onset feelings of gender dysphoria may be a consequence of increased media visibility and societal acceptance of transgender identity as well as awareness of medical treatment options [36], but concerns have also been raised about possible too hasty proceeding towards medical treatments among young natal females with rapid onset gender identity issues [13]. As the proportions of those identifying with the opposite sex and with other/non-binary gender identity among girls decreased from early to middle and late adolescence, the present findings suggest that some transgender identifications in adolescent girls may represent identity explorations rather than consolidated identity $[21,24,25]$. Identity explorations are a part of normative adolescent development.

A strength of the present study is the uniquely large population sample including respondents in different phases of adolescence. As has been recommended [17,18], we used a two-step approach to identify subjects with different gender identities, eliciting sex and gender perception separately. Eliciting sex was the opening question of the whole survey, and perceived gender was elicited in the section on health after eliciting perceived health, height and weight. The possibility that some respondents with strong identification with the opposite sex indicated perceived gender rather than natal sex already in the first step cannot be controlled for, as has been the case in earlier corresponding studies [15,17]. This is a limitation inherent in the anonymous survey method and a limitation in the present study. Most likely the respondents understood that the first question (What is your sex?) referred to sex as indicated in identity documents, as this is the case in any official documents and forms in Finland, but it is unfortunately not possible check whether some respondents possibly indicated perceived gender already in that phase of the survey, not to estimate their number.

Analysing implausible and potentially mischievous responding and presenting prevalences corrected for it is a strength of the present study. It is of course possible that some facetious responders were still included in the analyses and may thus distort the estimates of the various gender identities. As it was shown that likely implausible responding particularly influenced other/non-binary gender identification, the possible bias can be assumed to be most influential regarding estimates of other/nonbinary gender identification, thereby making the estimates higher than in reality. A limitation is that our data did not include adolescents not in education. Adolescents in Finland participate in compulsory education up to the age of 16 , but of those aged 17-24, about $8 \%$, are outside education (have not completed and are currently not in upper secondary or higher education) [37]. According to theories of identity development [21,22,23], those outside education could be assumed to display identity diffusion more commonly than their peers who are integrated in ageappropriate commitments, but we are not aware of studies focused on gender identity among them.

Of the respondents, $1.5 \%$ did not answer the question on perceived gender and could not be assigned to any of the three gender identity categories used in the present study. Omitting this item could indicate uncertainty about gender identity. However, omitting this item was actually less common than omitting other, perhaps less sensitive items such as perceived health or height. Therefore we decided to not make any assumptions about omitting this item.

\section{Conclusion}

Of Finnish adolescents younger than $21,0.6 \%$ report identifying with the opposite sex, and 3.3\% report identifying with both boys and girls or with neither, or that their perception of their own gender varies. The proportion of other than cis-gender identity increases from younger adolescents to older among boys but decreases among girls. Reporting transgender identity is susceptible to unreliable responding in adolescent survey studies, particularly among boys and younger adolescents. In order to obtain valid information on the prevalence of various gender 
identities and the well-being of transgender youth, methods are needed which allow for implausible, unreliable responses.

\section{References}

[1] American Psychiatric Association. Diagnostic and statistical manual of mental disorders. 5th ed. Washington DC: Author; 2013.

[2] World Health Organization. The ICD-10 classification of mental and behavioural disorders: clinical descriptions and diagnostic guidelines. Geneva: World Health Organization; 1992.

[3] Drescher J, Cohen-Kettenis PT, Reed GM. Gender incongruence of childhood in the ICD-11: controversies, proposal, and rationale. Lancet Psychiatry 2016;3 (Mar (3)):297-304.

[4] Collin L, Reisner SL, Tangpricha V, Goodman M. Prevalence of transgender depends on the "case" definition: a systematic review. J Sex Med 2016;13(April (4)):613-26.

[5] Gray SAO, Carter AS, Levitt H. A critical review of assumptions about gender variant children in psychological research. J Gay Lesbian Mental Health 2012;16(1) 4-5-30.

[6] Ristori J, Steensma TD. Gender dysphoria in childhood. Int Rev Psychiatry 2016;28(1):13-20.

[7] Cohen-Kettenis PT, Klink D. Adolescents with gender dysphoria. Baillieres Best Pract Res Clin Endocrinol Metab 2015;29(Jun (3)):485-95.

[8] Coleman E, Bockting W, Botzer M, Cohen-Kettenis P, DeCuypere G, Feldman J, et al. The standards of care of the world professional association for transgender health, 7th version. Int J Transgenderism 2011;13:165-232.

[9] Wood H, Sasaki S, Bradley SJ, Singh D, Fantus S, Owen-Anderson A, et al Patterns of referral to a gender identity service for children and adolescents (1976-2011): age, sex ratio, and sexual orientation. J Sex Marital Ther 2013;39 (1):1-6.

[10] Aitken M, Steensma TD, Blanchard R, VanderLaan DP, Wood H, Fuentes A, et al. Evidence for an altered sex ratio in clinic-referred adolescents with gender dysphoria. J Sex Med 2015;12(Mar (3)):756-63.

[11] Kaltiala-Heino R, Sumia M, Tyolajarvi M, Lindberg N. Two years of gender identity service for minors: overrepresentation of natal girls with severe problems in adolescent development. Child Adolesc Psychiatry Ment Health 2015;9:9.

[12] Kaltiala-Heino R, Bergman H, Tyolajarvi M, Frisen L. Gender dysphoria in adolescence: current perspectives. Adolesc Health Med Ther 2018;9:31-41.

[13] Marchiano L. Outbreak: on transgender teens and psychic epidemics. Psychol Persp 2017;60: 345-346-366.

[14] Shields JP, Cohen R, Glassman JR, Whitaker K, Franks H, Bertolini I. Estimating population size and demographic characteristics of lesbian, gay, bisexual, and transgender youth in middle school. J Adolesc Health 2013:52(Feb (2)):248-50.

[15] Clark TC, Lucassen MFG, Bullen P, Denny SJ, Fleming TM, Robinson EM, et al. The health and well-being of transgender high school students: results from the New Zealand adolescent health survey (youth'12). J Adolesc Health 2014;55(Jul (1)):93-9.

[16] Diemer EW, Grant JD, Munn-Chernoff MA, Patterson DA, Duncan AE. Gender identity, sexual orientation, and eating-related pathology in a national sample of College students. J Adolesc Health 2015;57(Aug (2)):144-9.
[17] Eisenberg ME, Gower AL, McMorris BJ, Rider GN, Shea G, Coleman E. Risk and protective factors in the lives of Transgender/Gender nonconforming adolescents. J Adolesc Health 2017;61(Oct (4)):521-6.

[18] Reisner SL, Conron KJ, Tardiff LA, Jarvi S, Gordon AR, Austin SB. Monitoring the health of transgender and other gender minority populations: validity of natal sex and gender identity survey items in a U.S. National cohort of young adults. BMC Public Health 2014;26(Nov (14)):1224.

[19] Becker I, Ravens-Sieberer U, Ottova-Jordan V, Schulte-Markwort M. Prevalence of adolescent gender experiences and gender expression in Germany. J Adolesc Health 2017;61(Jul (1)):83-90.

[20] Sumia M, Lindberg N, Tyolajarvi M, Kaltiala-Heino R Current and recalled childhood gender identity in community youth in comparison to referred adolescents seeking sex reassignment. J Adolesc 2017;56(Apr):34-9.

[21] Kroger J. Identity development. Adolescence through adulthood. 2nd ed. Thousand Oaks, California: Sage Publications; 2007.

[22] Erikson E. Identity, youth and crisis. London: Faber Faber; 1968.

[23] Marcia JE. Development and validation of ego-identity status. J Pers Soc Psychol 1966;3(May (5)):551-8.

[24] Kroger J, Martinussen M, Marcia JE. Identity status change during adolescence and young adulthood: a meta-analysis. J Adolesc 2010;33(Oct (5)):683-98.

[25] Moshman D. Adolescent rationality and development. Ccognition, morality, and identity. New York: Psychology Press; 2011.

[26] Robinson-Cimpian JP. Inaccurate estimation of disparities due to mischievous responders: several suggestions to assess conclusions. Educ Res 2014;43(4) 171-172-185.

[27] Fan X, Miller BC, Park K, Winward BW, Christensen M, Grotevant HD, et al. An exploratory study about inaccuracy and invalidity in adolescent self-report surveys. Field Methods 2006;18: 223-224-244.

[28] Cornell D, Klein J, Konold T, Huang F. Effects of validity screening items on adolescent survey data. Psychol Assess 2012;24(Mar (1)):21-35.

[29] Blos P. On adolescence. A psychodynamic interpretation. New York: Free Press; 1962.

[30] Sanders RA. Adolescent psychosocial, social, and cognitive development Pediatr Rev 2013;34(Aug (8)):354-8.

[31] Cea D, Ancona MA. Measuring multiple discrimination through a survey-based methodology. Soc Sci Res 2017;67(Sep):239-51.

[32] Chesir-Teran D, Hughes D. Heterosexism in high school and victimization among lesbian, gay, bisexual, and questioning students. J Youth Adolesc 2009;38(Aug (7)):963-75.

[33] Dunn TL, Szymanski DM. Heterosexist discrimination and LGBQ activism: examining a moderated mediation model. Psychol Sexual Orientation Gender Diversity 2018;5(1):13-24.

[34] Fechner PY. Gender differences in puberty. J Adolesc Health 2002;30(Apr (4 Suppl)):44-8

[35] Klimstra TA, Hale WW, Raaijmakers QAW, Branje SJT, Meeus WHJ. Maturation of personality in adolescence. J Pers Soc Psychol 2009:96(Apr (4)):898-912.

[36] Arcelus J, Bouman WP, Van Den Noortgate W, Claes L, Witcomb G, FernandezAranda F. Systematic review and meta-analysis of prevalence studies in transsexualism. Eur Psychiatry: J Assoc Eur Psychiatrists 2015;30(Sep (6)):807-15.

[37] Hyvinvointikompassi. 2018. . Referenced in 27.5.2018 https://www. hyvinvointikompassi.fi/web/hyvinvointikompassi/indikaattori/-/indicator/r/ $658 / \mathrm{c} / 658 / \mathrm{g} / \mathrm{total} / \mathrm{i} / 3219$. 